\title{
GERMINAÇÃO DE SEMENTES DE Acacia polyphylla DC. (MONJOLEIRO) E DE Aspidosperma ramiflorum Müll. Arg. (GUATAMBU)
}

\author{
Antonio da Silva*, Márcia Balistiero Figliolia**, Ivor Bergemann de Aguiar*** \\ *Biólogo, Doutorando em Ecologia, UFSCAR, Seção de Silvicultura, IFSP - asilva@iflorestal.sp.gov.br \\ **Eng ${ }^{\mathrm{a}}$. Florestal, Dr ${ }^{\mathrm{a}}$., Seção de Silvicultura, IFSP - mafigliolia@iflorestal.sp.gov.br \\ ***Eng. Agrônomo, Dr., Depto. de Produção Vegetal, FCAV/UNESP - ivor@netsite.com.br \\ Recebido para publicação: 04/01/2007 - Aceito para publicação: 11/04/2007
}

\begin{abstract}
Resumo
Foram estudados os efeitos da temperatura, qualidade de luz e umidade do substrato na germinação de sementes de Acacia polyphylla (monjoleiro) e Aspidosperma ramiflorum (guatambu). As sementes de monjoleiro foram umedecidas com 30, 60 e $90 \mathrm{~mL}$ de água destilada e incubadas a 20, 25, 30 e 20-30 ${ }^{\circ} \mathrm{C}$, na ausência de luz e sob luz dos espectros branco e verde. As sementes de guatambu foram umedecidas com 45, 90 e $135 \mathrm{~mL}$ de água destilada e incubadas a 25,30 e 20-30 ${ }^{\circ} \mathrm{C}$, na ausência de luz e na presença de luz dos espectros branco, vermelho e vermelho-extremo. Utilizaram-se como substrato $30 \mathrm{~g}$ de vermiculita média, tendo sido avaliados a porcentagem e o índice de velocidade de germinação. As sementes das duas espécies apresentaram elevada germinação nas condições testadas, sugerindo que as plântulas resultantes em laboratório sejam capazes de, em condições naturais, se estabelecerem tanto em clareira quanto sob o dossel da floresta. Os testes de germinação podem ser conduzidos com fotoperíodo de oito horas sob luz branca, a 25 ou $20-30{ }^{\circ} \mathrm{C}$ e com $30 \mathrm{~mL}$ de água para monjoleiro, e a 25 ou $30^{\circ} \mathrm{C}$ e com $90 \mathrm{~mL}$ de água para guatambu.

Palavras-chave: Semente florestal; qualidade fisiológica; temperatura; luz; umidade do substrato.
\end{abstract}

\begin{abstract}
Germination of Acacia polyphylla DC. and Aspidosperma ramiflorum Müll. Arg. seeds. The effects of temperature, light quality and substrate moisture on seed germination of two Brazilian tree species, Acacia polyphylla (Fabaceae) and Aspidosperma ramiflorum (Apocynaceae), were studied. Vermiculite ( $30 \mathrm{~g} /$ gerbox) was used as substrate, moistened with 30,60 and $90 \mathrm{~mL}$ of distilled water for A. polyphylla and 45, 90 and $135 \mathrm{~mL}$ for A. ramiflorum. Seeds of the first species were incubated at $20,25,30$ and $20-30{ }^{\circ} \mathrm{C}$, in darkness and under white and green lights, while those of the second species were incubated at 25,30 and $20-30{ }^{\circ} \mathrm{C}$, in darkness and under white, red and far-red lights. Both germination percentage and speed index were evaluated. Under all tested conditions, seeds of both species presented high germination, suggesting that the produced seedlings under laboratory conditions are able to establish, in natural conditions, either in light gap or under canopy. Under laboratory conditions, germination tests can be performed at an eight hours photoperiod under white light for both species, at 25 or $20-30{ }^{\circ} \mathrm{C}$ with $30 \mathrm{~mL}$ of water for Acacia polyphylla and at 25 or $30{ }^{\circ} \mathrm{C}$ with $90 \mathrm{~mL}$ of water for Aspidosperma ramiflorum.
\end{abstract}

Keywords: Forest seed; physiological quality; temperature; light; substrate moisture.

\section{INTRODUÇÃO}

A temperatura e a luz são dois importantes fatores ambientais que controlam a germinação das sementes (TOOLE, 1973), e pesquisas sobre o efeito desses fatores na germinação de sementes de espécies florestais nativas do Brasil vêm sendo publicadas desde o início da década de 80 . Adicionalmente, a umidade do solo é outro importante fator, controlando o início da germinação, uma vez que as sementes precisam ser embebidas em água para germinar (BASKIN; BASKIN, 1988).

Para a adequada condução do teste de germinação de sementes em laboratório, são recomendadas condições controladas desses três fatores (BRASIL, 1992; FIGLIOLIA et al., 1993; 
FIGLIOLIA; PIÑA-RODRIGUES, 1995; PIÑA-RODRIGUES et al., 2004). As pesquisas que incluíram a umidade do substrato como um terceiro fator, afetando a germinação de sementes florestais nativas, são mais escassas e recentes, tendo sido realizadas com Genipa americana L. (jenipapo), por Figliolia e Silva (1998); Schinus terebinthifolius Raddi (aroeira-vermelha), por Silva et al. (2001); Gallesia integrifolia (Spreng.) Harms (pau-d'alho), por Barros et al. (2005); Lafoensia glyptocarpa Koehne (mirindiba-rosa), Myroxylon peruiferum L. f. (cabreúva-vermelha) e Cedrela fissilis Vell. (cedro-rosa), por Figliolia et al. (2006). Apenas no trabalho desenvolvido com Schinus terebinthifolius o papel de filtro foi utilizado como substrato; para as demais espécies, o substrato adotado foi a vermiculita.

A temperatura influencia a germinação por agir tanto sobre a velocidade de absorção de água como também sobre as reações bioquímicas que determinam todo o processo germinativo (CARVALHO; NAKAGAWA, 2000). As sementes classificadas como ortodoxas são dispersas, com baixo teor de água, sendo necessário o umedecimento do substrato para a reabsorção de água, a fim de possibilitar o reinício das atividades metabólicas (CASTRO et al., 2004). De acordo com as respostas das sementes à luz, elas são classificadas em fotoblásticas positivas (beneficiadas pela luz), fotoblásticas negativas (prejudicadas pela luz) e não-fotoblásticas, que são indiferentes ou insensíveis à luz (MARCOS FILHO, 2005).

A germinação das sementes, em função dos fatores ambientais, está associada às características ecofisiológicas das espécies. Assim, sementes de espécies pertencentes a um grupo ecológico podem necessitar de condições diferentes das de outro grupo ecológico, para expressar seu maior potencial germinativo.

Acacia polyphylla DC. (monjoleiro) pertence ao grupo ecológico das espécies secundárias iniciais (FERRETTI et al., 1995). É uma espécie arbórea de médio porte (15 a $20 \mathrm{~m}$ de altura), da família Fabaceae, que ocorre naturalmente desde a região amazônica até o Paraná, na floresta latifoliada semidecídua. Encontra-se também dispersa nas florestas primárias da bacia do rio Paraná. Nas formações secundárias, sua ocorrência é expressiva em todos os estádios sucessionais, particularmente nas encostas e topos de morros de terrenos pedregosos e secos. Sua madeira é apropriada para marcenaria, torno e obras internas, e a casca serve para curtir o couro. É uma espécie rústica e recomendada para recuperação de áreas de preservação permanente (LORENZI, 2002a).

Araújo Neto et al. (2003) estudaram o efeito da temperatura e da luz na germinação das sementes de Acacia polyphylla, mas não estudaram o efeito da umidade do substrato. Os autores testaram as temperaturas constantes de $15,20,25$ e $30^{\circ} \mathrm{C}$, bem como a temperatura alternada de $20-30{ }^{\circ} \mathrm{C}$, sob fotoperíodo de oito horas sob luz branca. Maiores porcentagem e velocidade de germinação foram constatadas nas temperaturas constantes de 25 e $30{ }^{\circ} \mathrm{C}$, e os autores selecionaram a temperatura de $25^{\circ} \mathrm{C}$ para conduzir mais dois experimentos. No primeiro experimento foram testados fotoperíodos de 0 a 12 horas, sob luz branca, e os resultados mostraram que fotoperíodo igual ou superior a quatro horas favoreceu a velocidade de germinação das sementes. No segundo experimento as sementes foram submetidas à ausência de luz e a fotoperíodos sob luz branca iniciados e finalizados com luz de sombreamento (baixa relação vermelho/vermelho-extremo). A germinação não foi afetada pela luz de sombreamento, mas na ausência de luz as sementes germinaram em menores porcentagem e velocidade.

Aspidosperma ramiflorum Müll. Arg. pertence aos estádios finais da sucessão secundária, sendo denominada de matiambu e classificada como clímax por Cordini (1994) em Santa Catarina, e denominada de guatambu e classificada como secundária tardia por Ferretti et al. (1995) em São Paulo. É uma espécie arbórea de maior porte (20 a $30 \mathrm{~m}$ de altura), da família Apocynaceae, típica da floresta clímax. Ocorre naturalmente dos estados do Rio de Janeiro e Minas Gerais até o de Santa Catarina, na floresta pluvial da encosta atlântica, e também de maneira esparsa na floresta semidecídua de altitude. Produz madeira apropriada principalmente para a construção civil, vem sendo utilizada na arborização urbana e é útil para reflorestamentos mistos destinados à recuperação de áreas degradadas (LORENZI, $2002 b)$.

Estudando o armazenamento de sementes de Aspidosperma ramiflorum em diferentes ambientes, Silva (1991) testou, em um ensaio preliminar, as temperaturas constantes de $20,25,30$ e $35{ }^{\circ} \mathrm{C}$ e constatou que a porcentagem de germinação foi menor em $35^{\circ} \mathrm{C}(74 \%)$ do que nas outras temperaturas (93 a 97\%). Nenhuma referência sobre o efeito da temperatura alternada, bem como da luz e da umidade do substrato, foi encontrada na literatura consultada.

Este trabalho foi desenvolvido com o objetivo de estudar a influência da luz, temperatura e umidade do substrato da germinação das sementes de Acacia polyphylla e Aspidosperma ramiflorum, 
bem como a interação entre eles. Os resultados obtidos poderão contribuir para se compreender a germinação das sementes dessas espécies em ambientes naturais, assim como recomendar as condições a serem adotadas pelos laboratórios na condução dos testes de qualidade fisiológica das sementes.

\section{MATERIAL E MÉTODOS}

As sementes utilizadas neste trabalho foram extraídas de frutos colhidos de árvores matrizes das Estações Experimentais do Instituto Florestal de São Paulo, localizadas no interior do estado. Após a extração e o beneficiamento, as sementes foram armazenadas na câmara-fria $\left(\mathrm{T}=5{ }^{\circ} \mathrm{C}\right.$ e UR $\left.=85 \%\right)$ do Centro de Sementes desse Instituto, localizado na capital do estado, até a instalação dos experimentos, que foram desenvolvidos no Laboratório de Sementes desse Centro.

Os frutos de Aspidosperma ramiflorum (guatambu) foram colhidos em julho de 1997 na Estação de Bauru, situada a 22 $19^{\prime} \mathrm{S}$ e $49^{\circ} 04^{\prime} \mathrm{W}$, com altitude média de $570 \mathrm{~m}$ e clima Aw (VENTURA et al., 1965/66). Os frutos de Acacia polyphylla (monjoleiro) foram colhidos em agosto de 1998 na Estação de Paulo de Faria, situada a $19^{\circ} 58^{\prime} \mathrm{S}$ e $49^{\circ} 32^{\prime}$ W. A altitude varia de 400 a $495 \mathrm{~m}$ e o clima se caracteriza por uma estação seca de abril a setembro e outra chuvosa de outubro a março (STRANGHETTI; RANGA, 1998).

Os testes de germinação foram conduzidos em germinadores de câmara tipo BOD, contendo quatro lâmpadas fluorescentes de $20 \mathrm{~W}$, sendo as sementes colocadas sobre $30 \mathrm{~g}$ de vermiculita de granulometria média, em caixas plásticas de $11 \times 11 \times 4 \mathrm{~cm}$, com tampa.

Foram utilizadas quatro repetições de 25 sementes para monjoleiro, sendo o substrato umedecido com 30, 60 e $90 \mathrm{~mL}$ de água destilada. Os germinadores foram regulados para as temperaturas constantes de 20,25 e $30^{\circ} \mathrm{C}$ e alternada de $20-30{ }^{\circ} \mathrm{C}$, na ausência de luz e sob luz dos espectros branco e verde, simultaneamente. O período de duração dos testes de germinação foi de 14 dias.

Para guatambu, foram adotadas quatro repetições de 16 sementes colocadas sobre o substrato umedecido com 45, 90 e $135 \mathrm{~mL}$ de água destilada. Os germinadores foram regulados para as temperaturas constantes de 25 e $30^{\circ} \mathrm{C}$ e alternada de $20-30{ }^{\circ} \mathrm{C}$, na ausência de luz e sob luz dos espectros branco, vermelho e vermelho-extremo, simultaneamente. Os testes de germinação tiveram a duração de 33 dias.

Para as duas espécies, o fotoperíodo foi de oito horas, e no caso da temperatura alternada, o período referente à ausência de luz correspondeu à temperatura de $20^{\circ} \mathrm{C}$ e o período sob luz à de $30^{\circ} \mathrm{C}$.

No tratamento referente à ausência de luz foram utilizadas caixas de coloração preta envolvidas em papel alumínio, enquanto que na presença de luz foram utilizadas caixas transparentes. No tratamento referente à luz branca, as caixas não foram envolvidas por papel celofane. Nos demais tratamentos, as caixas foram envolvidas por duas folhas de papel de coloração vermelha (espectro vermelho) e cinco folhas (três de coloração azul e duas de coloração vermelha) para a luz do espectro vermelho-extremo. De acordo com Valio e Scarpa (2001), esses conjuntos proporcionam razão V/VE de 0,6 e de 0,1, respectivamente. A instalação e a avaliação do tratamento de luz branca foram feitas sob iluminação normal de laboratório, enquanto que para os demais tratamentos essas operações foram realizadas em ambiente iluminado com duas lâmpadas fluorescentes envolvidas por duas folhas de papel celofane verde. Todos esses procedimentos foram adotados com base em Silva et al. (1997). Para a germinação sob luz verde, as caixas plásticas foram envolvidas por duas folhas de papel celofane de coloração verde (espectro de $0,02 \mu \mathrm{W} . \mathrm{cm}^{-2} . \mathrm{nm}$ ), segundo Lopes e Soares (2003).

Foram feitas contagens diárias das sementes germinadas, considerando o critério silvicultural de germinação (emissão da raiz primária e do primeiro par de folhas). A qualidade fisiológica das sementes foi avaliada em termos de capacidade (porcentagem final) e velocidade de germinação. A velocidade de germinação, calculada com base em Maguire (1962), foi obtida pelo somatório do número de sementes germinadas em cada contagem, dividido pelo número de dias correspondente à respectiva contagem.

Os experimentos foram instalados seguindo o delineamento inteiramente casualizado e as análises de variância foram efetuadas sob o esquema fatorial. Os fatores testados foram temperatura, qualidade de luz e umidade do substrato. Nessa ordem, foram adotados os esquemas $4 \times 3 \times 3$ para monjoleiro e $3 \times 4 \times 3$ para guatambu. Os dados originais foram analisados sem transformação, e as médias foram comparadas pelo teste de Tukey, no nível de 5\% de probabilidade (PIMENTEL-GOMES; GARCIA, 2002). 


\section{RESULTADOS E DISCUSSÃO}

A capacidade germinativa das sementes de monjoleiro não foi afetada pela luz, mas foi influenciada pela temperatura e pela umidade do substrato (Tabela 1). A interação entre esses três fatores não foi significativa.

Tabela 1. Porcentagem de germinação (\%G) das sementes de Acacia polyphylla (monjoleiro) submetidas a diferentes temperaturas, qualidades de luz e níveis de umidade do substrato.

Table 1. Germination percentage (\%G) of Acacia polyphylla seeds submitted to different temperature, light quality and substrate moisture levels.

\begin{tabular}{lcl}
\hline Fator & Nível & \%G \\
\hline \multirow{4}{*}{ Temperatura } & $20{ }^{\circ} \mathrm{C}$ & $84 \mathrm{ab}$ \\
& $25{ }^{\circ} \mathrm{C}$ & $84 \mathrm{ab}$ \\
& $30{ }^{\circ} \mathrm{C}$ & $80 \mathrm{~b}$ \\
Qualidade de luz & $20-30{ }^{\circ} \mathrm{C}$ & $87 \mathrm{a}$ \\
\hline \multirow{3}{*}{ Umidade do substrato } & Ausente & $83 \mathrm{a}$ \\
& Branca & $84 \mathrm{a}$ \\
& Verde & $85 \mathrm{a}$ \\
\hline
\end{tabular}

$\mathrm{F} \mathrm{p} /$ temperatura $(\mathrm{T}): 3,41^{*} ; \mathrm{F} \mathrm{p} /$ interação $(\mathrm{T} \times \mathrm{L}): 1,07^{\text {ns }} ; \mathrm{F}$ p/ qualidade de luz $(\mathrm{L}): ; 0,60^{\text {ns }} ; \mathrm{F}$ p/ interação $(\mathrm{T} \times \mathrm{U}): 0,31^{\text {ns }} ; \mathrm{F}$ p/ umidade do substrato $(\mathrm{U})$ : $33,87^{* *} ; \mathrm{F}$ p/ interação (L x U): $0,77^{\text {ns }}$; Coeficiente de variação: $10,38 \% ; a, b$ : Letras comparam médias de cada fator, a $5 \%$ de probabilidade; ns: nãosignificativo: $\mathrm{P}>0,05 ; *$ significativo: $\mathrm{P}<0,05 ; * *$ significativo: $\mathrm{P}<0,01$.

A luz verde é considerada de segurança, por ser neutra e não afetar a germinação, sendo recomendada para a realização das contagens de sementes germinadas sob diferentes qualidades de luz (SOUZA; PEREIRA, 1992). O resultado que chamou a atenção foi a elevada germinação na ausência de luz (83\%), diferindo do obtido por Araújo Neto et al. (2003) com essa mesma espécie, em que, na ausência de luz, a capacidade de germinação (41\%) foi muito inferior à constatada sob luz branca (81 a 91\%).

A temperatura teve pouco efeito na capacidade germinativa das sementes (Tabela 1), que tendeu a ser favorecida pelo regime alternado. Embora com elevada porcentagem, apenas na temperatura constante de $30^{\circ} \mathrm{C}(80 \%)$ a germinação foi significativamente inferior à obtida a $20-30{ }^{\circ} \mathrm{C}(87 \%)$. Esses resultados também diferiram dos verificados por Araújo Neto et al. (2003), que não constataram diferença significativa entre os valores de porcentagem de germinação obtidos nas temperaturas constantes de 25 e $30{ }^{\circ} \mathrm{C}$ e na alternada de $20-30{ }^{\circ} \mathrm{C}$.

No presente trabalho, as sementes submetidas à luz branca germinaram com a mesma velocidade nas temperaturas constantes de 25 e $30{ }^{\circ} \mathrm{C}$ e na alternada de $20-30{ }^{\circ} \mathrm{C}$ (Tabela 2). Araújo Neto et al. (2003), contudo, verificaram que, na temperatura constante de $25^{\circ} \mathrm{C}$, a velocidade de germinação das sementes, sob luz branca, foi significativamente superior à constatada na temperatura alternada.

Observa-se nessa tabela que, nessas três temperaturas $\left(25^{\circ} \mathrm{C}, 30^{\circ} \mathrm{C}\right.$ e $\left.20-30{ }^{\circ} \mathrm{C}\right)$, as sementes submetidas à luz dos espectros branco e verde germinaram mais rapidamente do que na ausência de luz. A porcentagem de germinação a $30^{\circ} \mathrm{C}$ (Tabela 1) e a velocidade de germinação sob luz branca a $20{ }^{\circ} \mathrm{C}$ tenderam a ser menores (Tabela 2), concordando com os resultados obtidos por Araújo Neto et al. (2003). Segundo Carvalho e Nakagawa (2000), temperaturas acima da ótima, para a porcentagem de germinação, aceleram e desorganizam o processo germinativo, enquanto que temperaturas abaixo da ótima tendem a reduzir a velocidade de germinação.

As diferenças verificadas entre os resultados obtidos neste trabalho e no realizado por Araújo Neto et al. (2003), com a mesma espécie, podem ter sido causadas pelas diferentes condições climáticas às quais as plantas-mães foram submetidas durante os períodos de formação e maturação das sementes, uma vez que os lotes utilizados em cada trabalho foram colhidos em locais e anos distintos. De acordo com Labouriau (1983), as diferenças nas condições climáticas ocorridas nesses períodos podem modificar o comportamento germinativo das sementes. 
Tabela 2. Índice de velocidade de germinação das sementes de Acacia polyphylla (monjoleiro) submetidas a diferentes temperaturas, qualidades de luz e níveis de umidade do substrato.

Table 2. Germination speed index of Acacia polyphylla seeds submitted to different temperature, light quality and substrate moisture levels.

\begin{tabular}{|c|c|c|c|c|}
\hline \multirow{2}{*}{ Fator } & \multirow{2}{*}{ Nível } & \multicolumn{3}{|c|}{ Qualidade de luz } \\
\hline & & Ausência & Branca & Verde \\
\hline \multirow{4}{*}{ Temperatura } & $20^{\circ} \mathrm{C}$ & $9,6 \mathrm{a} \quad \mathrm{A}$ & $9,7 \quad \mathrm{~b} \mathrm{~A}$ & 10,2 a $\mathrm{A}$ \\
\hline & $25{ }^{\circ} \mathrm{C}$ & $9,0 \mathrm{ab} \quad \mathrm{B}$ & $10,0 \mathrm{ab} A$ & 10,7 a $\mathrm{A}$ \\
\hline & $30{ }^{\circ} \mathrm{C}$ & $8,4 \mathrm{~b} \quad \mathrm{~B}$ & $10,8 \mathrm{a} \quad \mathrm{A}$ & 10,5 a $\mathrm{A}$ \\
\hline & $20-30{ }^{\circ} \mathrm{C}$ & $9,1 \mathrm{ab} \quad \mathrm{B}$ & $10,4 \mathrm{ab} A$ & 10,2 a $\mathrm{A}$ \\
\hline \multirow{3}{*}{ Umidade do substrato } & $30 \mathrm{~mL}$ & $10,0 \mathrm{a}$ & $11,7 \mathrm{a} \quad \mathrm{A}$ & $10,9 \mathrm{a} \quad \mathrm{B}$ \\
\hline & $60 \mathrm{~mL}$ & $9,1 \quad b \quad C$ & $9,9 \quad \mathrm{~b} \quad \mathrm{~B}$ & 10,6 a $\mathrm{A}$ \\
\hline & $90 \mathrm{~mL}$ & $8,1 \quad$ c $B$ & $9,2 \quad \mathrm{c} \mathrm{A}$ & 9,7 b A \\
\hline
\end{tabular}

F p/ temperatura (T): $0,03^{\text {ns }} ; \mathrm{F}$ p/interação (T x L): 4,66**; F p/ qualidade de luz (L): 39,77**; F p/ interação (T x U): 1,91 ${ }^{\text {ns }} ; \mathrm{F}$ p/ umidade do substrato (U): 63,90**; F p/ interação (L x U): 3,67**; Coeficiente de variação: 8,27 \%; $A, B$ : Em cada linha, letras maiúsculas comparam médias de qualidade de luz, a $5 \%$ de probabilidade; $a, b$ : Em cada coluna, letras minúsculas comparam médias de cada fator, a $5 \%$ de probabilidade; ns: não-significativo: $\mathrm{P}>0,05$; $*$ significativo: $\mathrm{P}<0,01$.

A umidade do substrato teve efeito mais marcante na germinação das sementes de monjoleiro do que os outros dois fatores testados. A porcentagem de germinação decresceu significativamente com o aumento do volume de água adicionado ao substrato (Tabela 1). Da mesma forma, as sementes germinaram em maior velocidade no substrato menos úmido (30 $\mathrm{mL}$ de água), como pode ser observado na tabela 2. O substrato, exceto para as espécies com maior exigência de umidade, nunca deve ficar úmido a ponto de formar uma película de água em torno da semente (FIGLIOLIA et al., 1993). O excesso de água, em geral, provoca decréscimo na germinação, pois impede a penetração de oxigênio e reduz todo o processo metabólico resultante (BORGES; RENA, 1993).

Para as sementes de guatambu, a interação entre a temperatura e os outros dois fatores testados (qualidade de luz e umidade do substrato) foi significativa para a porcentagem de germinação (Tabela 3). Sob luz branca, a capacidade germinativa das sementes incubadas a 25 e $30{ }^{\circ} \mathrm{C}$ foi bastante elevada, concordando com os resultados obtidos anteriormente por Silva (1991).

Tabela 3. Porcentagem de germinação das sementes de Aspidosperma ramiflorum (guatambu) submetidas a diferentes temperaturas, qualidades de luz e níveis de umidade do substrato.

Table 3. Germination percentage of Aspidosperma ramiflorum seeds submitted to different temperature, light quality and substrate moisture levels.

\begin{tabular}{|c|c|c|c|c|}
\hline \multirow{2}{*}{ Fator } & \multirow{2}{*}{ Nível } & \multicolumn{3}{|c|}{ Temperatura } \\
\hline & & $25^{\circ} \mathrm{C}$ & $30^{\circ} \mathrm{C}$ & $20-30{ }^{\circ} \mathrm{C}$ \\
\hline \multirow{4}{*}{ Qualidade de luz } & Ausente & 64 bc A & $70 \mathrm{~b} \mathrm{~A}$ & $68 \mathrm{~b} \mathrm{~A}$ \\
\hline & Branca & $96 \mathrm{a} A$ & 95 a A & 83 a $B$ \\
\hline & Vermelha & $76 \mathrm{~b} \quad \mathrm{~A}$ & $77 \mathrm{~b} \mathrm{~A}$ & $73 \mathrm{ab} A$ \\
\hline & Vermelho-extremo & 59 c $B$ & 79 b A & $74 \mathrm{ab} A$ \\
\hline \multirow[b]{2}{*}{ Umidade do substrato } & $45 \mathrm{~mL}$ & $71 \mathrm{~b} \quad \mathrm{~B}$ & 83 a $\mathrm{A}$ & $69 \mathrm{~b} \quad \mathrm{~B}$ \\
\hline & $90 \mathrm{~mL}$ & $82 \mathrm{a} \quad \mathrm{A}$ & 81 a $\mathrm{A}$ & $74 \mathrm{ab} B$ \\
\hline
\end{tabular}

F p/temperatura (T): 3,18*; F p/interação (T x L): 2,92**; F p/qualidade de luz (L): 24,60**; F p/interação (T x U): 4,08**; F p/umidade do substrato (U): $1,81^{\text {ns; }} \mathrm{F}$ p/interação (L x U): $1,25^{\text {ns }}$; Coeficiente de variação: $16,83 \% ; A, B$ : Em cada linha, letras maiúsculas comparam médias de temperatura, a $5 \%$ de probabilidade; $a, b$ : Em cada coluna, letras minúsculas comparam médias de cada fator, a 5\% de probabilidade; ns: não-significativo: $\mathrm{P}>0,05$; *: significativo: $\mathrm{P}<0,05$; **: significativo: $\mathrm{P}<0,01$.

Para as três temperaturas testadas, a maior porcentagem de germinação foi constatada sob luz branca. Nessa qualidade de luz, os menores valores foram obtidos na temperatura alternada de $20-30{ }^{\circ} \mathrm{C}$, e os maiores valores nas temperaturas constantes de 25 e $30{ }^{\circ} \mathrm{C}$. Na ausência de luz, a porcentagem de germinação foi semelhante à verificada sob luz dos espectros vermelho e vermelho-extremo.

Foi constatada interação significativa entre os três fatores testados para a velocidade de germinação das sementes (Tabela 4). Nas temperaturas de $25^{\circ} \mathrm{C}$ e $20-30{ }^{\circ} \mathrm{C}$, as sementes germinaram 
mais rapidamente sob luz branca, enquanto que a $30{ }^{\circ} \mathrm{C}$ a velocidade de germinação foi inferior na ausência de luz. Sob luz branca e na ausência de luz não houve efeito da temperatura, mas sob luz vermelha a germinação foi mais rápida a $30^{\circ} \mathrm{C}$, e sob luz do espectro vermelho-extremo a germinação foi mais lenta a $25^{\circ} \mathrm{C}$.

A umidade do substrato também desempenhou papel decisivo na germinação das sementes de guatambu. As sementes tenderam a germinar melhor quando o substrato foi umedecido com $90 \mathrm{~mL}$ de água.

A $30{ }^{\circ} \mathrm{C}$ não houve efeito da umidade na porcentagem de germinação (Tabela 3), mas a velocidade de germinação foi inferior com $45 \mathrm{~mL}$ de água (Tabela 4). A $25{ }^{\circ} \mathrm{C}$, maiores porcentagem e velocidade de germinação foram constatadas com $90 \mathrm{~mL}$ de água. Na temperatura alternada, as sementes germinaram em menor porcentagem em substrato menos úmido (45 $\mathrm{mL}$ de água) e em maior porcentagem em substrato mais úmido $(135 \mathrm{~mL}$ de água), mas nesta última condição a velocidade de germinação foi inferior.

Os resultados obtidos neste trabalho mostraram que as sementes das duas espécies estudadas germinaram em elevada porcentagem, em todas as condições testadas. Isso revela que, em condições naturais, as sementes possuem capacidade para germinar em diferentes condições de sombreamento, bem como de temperatura e umidade do solo. Comportamento semelhante foi observado para outras espécies arbóreas brasileiras, como Genipa americana (FIGLIOLIA; SILVA, 1998), Schinus terebinthifolius (SILVA et al., 2001), Gallesia integrifolia (BARROS et al., 2005), Lafoensia glyptocarpa, Myroxylon peruiferum e Cedrela fissilis (FIGLIOLIA et al., 2006).

Tabela 4. Índice de velocidade de germinação das sementes de Aspidosperma ramiflorum (guatambu) submetidas a diferentes temperaturas, qualidades de luz e níveis de umidade do substrato.

Table 4. Germination speed index of Aspidosperma ramiflorum seeds submitted to different temperature, light quality and substrate moisture levels.

\begin{tabular}{|c|c|c|c|c|}
\hline \multirow{2}{*}{ Fator } & \multirow{2}{*}{ Nível } & \multicolumn{3}{|c|}{ Temperatura } \\
\hline & & $25^{\circ} \mathrm{C}$ & $30^{\circ} \mathrm{C}$ & $20-30^{\circ} \mathrm{C}$ \\
\hline \multirow{4}{*}{ Qualidade de luz } & Ausente & 1,8 bc $\mathrm{A}$ & $2,0 \mathrm{~b} \mathrm{~A}$ & $2,0 \mathrm{~b} \mathrm{~A}$ \\
\hline & Branca & $2,7 \mathrm{a} \quad \mathrm{A}$ & 2,4 a $\mathrm{A}$ & 2,4 a $\mathrm{A}$ \\
\hline & Vermelha & $2,1 \mathrm{~b} \quad \mathrm{~B}$ & 2,5 a $A$ & $2,1 \mathrm{ab} \mathrm{B}$ \\
\hline & Vermelho-extremo & 1,6 c $\mathrm{B}$ & $2,3 \mathrm{ab} A$ & $2,0 \mathrm{~b} \mathrm{~A}$ \\
\hline \multirow{3}{*}{ Umidade do substrato } & $45 \mathrm{~mL}$ & $1,8 \mathrm{~b} \quad \mathrm{~B}$ & $2,1 \mathrm{~b} A$ & $2,3 \mathrm{ab} \mathrm{A}$ \\
\hline & $90 \mathrm{~mL}$ & $2,4 \mathrm{a} \quad \mathrm{A}$ & 2,5 a A & 2,5 a A \\
\hline & $135 \mathrm{~mL}$ & $1,9 \mathrm{~b} \mathrm{~A}$ & $2,3 \mathrm{ab} A$ & $2,1 \mathrm{~b} \mathrm{~A}$ \\
\hline
\end{tabular}

As sementes das espécies pertencentes aos estádios iniciais da sucessão secundária normalmente estão mais adaptadas para germinar em clareiras, onde há maior disponibilidade de luz, alternância da temperatura e menor umidade do solo (BAZZAZ; PICKETT, 1980; VÁZQUEZ-YANES; OROZCOSEGOVIA, 1984). Os resultados obtidos com monjoleiro concordam com suas características ecofisiológicas, pois se trata de espécie secundária inicial (FERRETTI et al., 1995) e suas sementes tenderam a germinar melhor na presença de luz, em temperatura alternada e em substrato menos úmido (Tabelas 1 e 2 ).

Os resultados obtidos com guatambu também concordam com suas características ecofisiológicas, pois a espécie pertence aos estádios finais da sucessão secundária (CORDINI, 1994; FERRETTI et al., 1995), que estão mais adaptadas a germinar sob o dossel, onde predominam a luz filtrada pela vegetação, temperatura constante e maior umidade do solo (BAZZAZ; PICKETT, 1980; VÁZQUEZ-YANES e OROZCO-SEGOVIA, 1984). No laboratório, suas sementes germinaram melhor em temperatura constante e em substrato mais úmido, embora sob luz branca (Tabelas 3 e 4).

$\mathrm{O}$ fato das duas espécies ter apresentado bom comportamento germinativo em todas as condições estudadas permite enquadrá-las nos dois grupos identificados por Kageyama e Gandara (2000): 
monjoleiro como pioneira antrópica (espécies não tipicamente pioneiras na floresta primária, mas que fazem o papel de pioneiras em áreas degradadas antrópicas) e guatambu como secundária/pioneira antrópica (espécies secundárias e normalmente raras na floresta primária, que em áreas antrópicas fazem o papel de pioneiras).

\section{CONCLUSÕES}

- Os resultados obtidos sob condições de laboratório permitem supor que, em condições naturais, as sementes das duas espécies estudadas sejam capazes de germinar tanto em clareira como sob o dossel da floresta.

- O teste de germinação com sementes de monjoleiro pode ser conduzido com fotoperíodo de oito horas sob luz branca, na temperatura constante de $25^{\circ} \mathrm{C}$ ou alternada de $20-30{ }^{\circ} \mathrm{C}$, e em substrato umedecido com $30 \mathrm{~mL}$ de água.

- O teste de germinação com sementes de guatambu pode ser conduzido com fotoperíodo de oito horas sob luz branca, nas temperaturas constantes de 25 ou $30^{\circ} \mathrm{C}$, e em substrato umedecido com $90 \mathrm{~mL}$ de água.

\section{REFERÊNCIAS}

ARAÚJO NETO, J.; AGUIAR, I. B.; FERREIRA, V. M. Efeito da temperatura e da luz na germinação de sementes de Acacia polyphylla DC. Revista Brasileira de Botânica, São Paulo, v. 26, n. 2, p. 249-256, 2003.

BARROS, S. S. U.; SILVA, A.; AGUIAR, I. B. Germinação de sementes de Gallesia integrifolia (Spreng.) Harms (pau-d'alho) sob diferentes condições de temperatura, luz e umidade do substrato. Revista Brasileira de Botânica, São Paulo, v. 28, n. 4, p. 727-733, 2005.

BASKIN, J. M.; BASKIN, C. C. Germination ecophysiology of herbaceous plant species in a temperate region. American Journal of Botany, Columbus, v. 75, n. 2, p. 286-305, 1988.

BAZZAZ, F. A.; PICKETT, S. T. A. Physiological ecology of tropical succession: a comparative review. Annual Review of Ecology and Systematic, Palo Alto, v. 11, p. 287-310, 1980.

BORGES, E. E. L.; RENA, A. B. Germinação de sementes. In: AGUIAR, I. B.; PIÑA-RODRIGUES, F. C. M.; FIGLIOLIA, M. B. Sementes florestais tropicais. Brasília: ABRATES, 1993. p. 83-135.

BRASIL. Ministério da Agricultura e da Reforma Agrária. Teste de germinação. In: Regras para análise de sementes. Brasília, DF: SNDA/DNDV/CLAV, 1992. p. 81-137.

CARVALHO, N. M.; NAKAGAWA, J. Germinação de sementes. In: Sementes: ciência, tecnologia e produção. 4. ed. Jaboticabal: FUNEP, 2000. p. 128-166.

CASTRO, R. D.; BRADFORD, K. J.; HILHORST, H. W. M. Embebição e reativação do metabolismo. In: FERREIRA, A. G.; BORGHETTI, F. Germinação: do básico ao aplicado. Porto Alegre: ARTMED, 2004. p. 149-162.

CORDINI, C. Grupos ecológicos de espécies florestais nativas de Santa Catarina. Agropecuária Catarinense, Florianópolis, v. 7, n. 1, p. 40-43, 1994.

FERRETTI, A. R.; KAGEYAMA, P. Y.; ÁRBOCZ, G. F.; SANTOS, J. D.; BARROS, M. I. A.; LORZA, R. F.; OLIVEIRA, C. Classificação das espécies arbóreas em grupos ecológicos para revegetação com nativas no Estado de São Paulo. Florestar Estatístico, São Paulo, v. 3, n. 7, p. 73-77, 1995.

FIGLIOLIA, M. B.; AGUIAR, I. B.; SILVA, A. Germinação de sementes de Lafoensia glyptocarpa Koehne (mirindiba-rosa), Myroxylon peruiferum L. f. (cabreúva-vermelha) e Cedrela fissilis Vell. (cedrorosa). Revista do Instituto Florestal, São Paulo, v. 18, n. único, p. 49-58, 2006. 
FIGLIOLIA, M. B.; OliveIRA, E. C.; PIÑA-RODRIGUES, F. C. M. Análise de sementes. In: AGUIAR, I. B.; PIÑA-RODRIGUES, F. C. M.; FIGLIOLIA, M. B. Sementes florestais tropicais. Brasília, DF: ABRATES, 1993. p. 137-174.

FIGLIOLIA, M. B.; PIÑA-RODRIGUES, F. C. M. Considerações práticas sobre o teste de germinação. IF Série Registros, São Paulo, n. 14, p. 14-45, 1995.

FIGLIOLIA, M. B.; SILVA, M. C. C. Germinação de sementes de jenipapeiro (Genipa americana L. Rubiaceae) sob diferentes regimes de temperatura, umidade e luz. Revista do Instituto Florestal, São Paulo, v. 10, n. 1, p. 63-72, 1998.

KAGEYAMA, P. Y.; GANDARA, F. B. Recuperação de áreas degradadas. In: RODRIGUES, R. R.; LEITÃO FILHO, H. F. Matas ciliares: conservação e recuperação. São Paulo: FAPESP, 2000. p. 249269.

LABOURIAU, L. G. A germinação das sementes. Washington: OEA, 1983. 174 p.

LOPES, J. C.; SOARES, A. S. Germinação de sementes de Miconia cinnamomifolia (Dc.) Naud. Brasil Florestal, Brasília, DF, n. 75, p. 31-38, 2003.

LORENZI, H. Acacia polyphylla DC. In: . Árvores brasileiras: manual de identificação e cultivo de plantas arbóreas nativas do Brasil. 4. ed. Nova Odessa: Instituto Plantarum, 2002a. v. 1, p. 185.

LORENZI, H. Aspidosperma ramiflorum Müll. Arg.. In: Árvores brasileiras: manual de identificação e cultivo de plantas arbóreas nativas do Brasil. 4. ed. Nova Odessa: Instituto Plantarum, 2002b. v. 1, p. 42.

MAGUIRE, J. D. Speed of germination-aid in selection and evaluation for seedling emergence and vigor. Crop Science, Madison, v. 2, n. 2, p. 176-177, 1962.

MARCOS FILHO, J. Germinação. In: Piracicaba: FEALQ, 2005. p. 197-252.

Fisiologia de sementes de plantas cultivadas.

PIMENTEL-GOMES, F.; GARCIA, C. H. Ensaios fatoriais. In: Estatística aplicada a experimentos agronômicos e florestais: exposição com exemplos e orientações para uso de aplicativos. Piracicaba: FEALQ, 2002. p. 117-149.

PIÑA-RODRIGUES, F. C. M.; FIGLIOLIA, M. B.; PEIXOTO, M. C. Testes de qualidade. In: FERREIRA, A. G.; BORGHETTI, F. Germinação: do básico ao aplicado. Porto Alegre: ARTMED, 2004. p. 283-297.

SILVA, A. Longevidade de sementes de Aspidosperma ramiflorum M. Arg., Apocynaceae, armazenadas em diferentes ambientes. Informativo ABRATES, Londrina, v. 1, n. 4, p. 88, 1991.

SILVA, A.; CASTELLANI, E. D.; AGUIAR, I. B.; SADER, R.; RODRIGUES, T. J. D. Interação entre luz e temperatura na germinação de sementes de Esenbeckia leiocarpa Engl. (guarantã). Revista do Instituto Florestal, São Paulo, v. 9, n. 1, p. 57-64, 1997.

SILVA, M. C. C.; NAKAGAWA, J.; FIGLIOLIA, M. B. Influência da temperatura, da luz e do teor de água na germinação de sementes de Schinus terebinthifolius Raddi - Anacardiaceae (aroeira-vermelha). Revista do Instituto Florestal, São Paulo, v. 13, n. 2, p. 135-146, 2001.

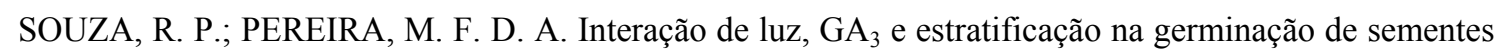
de Impatiens wallerana. Revista Brasileira de Fisiologia Vegetal, São Carlos, v. 4, n. 1, p. 21-25, 1992.

STRANGHETTI, V.; RANGA, N. T. Levantamento florístico das espécies vasculares da floresta estacional mesófila semidecídua da Estação Ecológica de Paulo de Faria - SP. Revista Brasileira de Botânica, São Paulo, v. 21, n. 3, p. 289-298, 1998.

TOOLE, V. K. Effects of light, temperature and their enteractions on the germination of seeds. Seed Science and Technology, Zürich, v. 1, n. 2, p. 339-396, 1973. 
VALIO, I. F. M.; SCARPA, F. M. Germination of seeds of tropical pioneer species under controlled and natural conditions. Revista Brasileira de Botânica, São Paulo, v. 24, n. 1, p. 79-84, 2001.

VÁZQUEZ-YANES, C.; OROZCO-SEGOVIA, A. Fisiología ecológica de las semillas de árboles de la selva tropical: un reflejo de su ambiente. Ciencia, Santo Domingo, v. 35, p. 191-201, 1984.

VENTURA, A.; BERENGUT, G.; VICTOR, M. A. M. Características das dependências do Serviço Florestal do Estado de São Paulo. Silvicultura em São Paulo, São Paulo, v. 4/5, n. 4, p. 57-140, 1965/66. 